\title{
PREDICTING THE UTILIZATION RATE AND RISK MEASURES OF COMMITTED CREDIT FACILITIES
}

\author{
Ihor Voloshyn ${ }^{1}$ \\ National Bank of Ukraine \\ Email: Ihor_Voloshyn@bank.gov.ua
}

\begin{abstract}
This study proposes a model for predicting the expected drawn amount of credit facilities. To model the committed credit facilities we rely on the conditional expected utilization rate derived from a joint truncated bivariate probability distribution. The expected monthly liquidity conversion factors for corporate credit lines are compared to actuals and the bivariate normal distribution is concluded to be appropriate for a practical estimate of the future utilization rate.
\end{abstract}

\section{JEL Codes: C58, G21, G32}

Keywords: utilization rate, committed credit facilities, exposure at default, credit conversion factor, liquidity conversion factor

\section{INTRODUCTION}

Committed credit facilities are key products offered by banks to corporate and retail clients, mainly in the form of irrevocable revolving lines of credit and current account overdraft facilities. Two important features of these products are the obligation by the bank to provide future commitments to the available credit and the right for clients to draw additional funds unless a credit limit has been reached. At the same time, the committed credit facilities can have a crucial impact on expected loan losses, capital, and liquidity ratios and a sudden drawdown in credit facilities creates both credit and liquidity risks. Because of the risks, the Basel Committee on Banking Supervision (BCBS), the European Banking Authority (EBA), the National Bank of Ukraine (NBU), and the new IFRS 9 establish rules for evaluating and recognizing credit facilities' risks (BIS, 2001, 2013; Regulation EU, 2013; NBU, 2016; IFRS 9).

This paper proposes a model for predicting the expected drawn amount of credit facilities based on the use of a conditional utilization rate derived from a joint truncated bivariate distribution.

The remainder of this paper is organized as follows: Section II outlines the target variables and model techniques used to estimate the expected drawn amount; Section III presents the approach to predicting the expected utilization rate based on a joint truncated bivariate distribution and examples of evaluating credit and liquidity risk measures; and Section IV provides the conclusions and direction for further investigation.

\section{LITERATURE REVIEW}

To predict the drawn amount of credit facilities, researchers have tested many different factors: the conversion factor, the utilization rate (limit usage), the change in utilization, and directly observed drawn amounts (Moral and de España, 2006; Taplin and al., 2007; Osipenko and Crook, 2015; Tong and al., 2016). However, there is no consensus among practitioners and researchers over which variables and techniques should be used for modelling.

The Basel Committee suggests using the Credit Conversion Factor (CCF) to calculate Exposure At Default (EAD) and a similar coefficient, the Liquidity Conversion Factor (LCF), to calculate the Liquidity Coverage Ratio (BIS, 2001, 2013). Therefore, the CCF is the ratio of the estimated Extra Drawn Amount $\left(E A D-B_{t}\right)$ during, according to Basel, the 12 months prior to default over the undrawn amount $\left(L-B_{t}\right)$ at current time $t$ (for instance, see Jacobs, 2009; Moral and de España, 2006):

${ }^{1}$ Acknowledgments. The author is very grateful to an anonymous reviewer for valuable comments and fruitful suggestions for improving the paper. 


$$
C C F=\frac{E A D-B_{t}}{L-B_{t}}
$$

where $E A D$ is the exposure at default, $L$ represents the credit limit, $B_{t}$ is the drawn amount of credit facilities at current time $t$. Note that under IFRS 9, the period of the $12^{\text {th }}$ month can be extended for the lifetime of a loan for certain types of impaired loans. The National Bank of Ukraine uses the CCF (NBU, 2016). The Liquidity Conversion Factor (LCF) differs from the CCF in that the extra drawn amount is estimated at a given time in the future. For instance, the LCF is predicted over a 30-day (monthly) horizon to estimate the Liquidity Coverage Ratio. It shows potential drawdowns as a percentage of off-balance sheet items (L-Bt) (BIS. 2013):

$$
L C F=\frac{E D A-B_{t}}{L-B_{t}}
$$

where EDA is the expected drawn amount at a given future time.

Thus, the credit facilities contain both on- and off-balance sheet items (Figure 1).

\section{Figure 1. The credit limit and the drawn and undrawn amounts of committed credit facilities}

Current, $t$

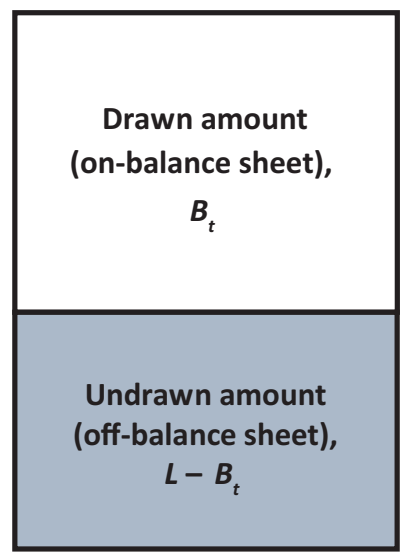

Developed by the author.
Future, $t+\tau$

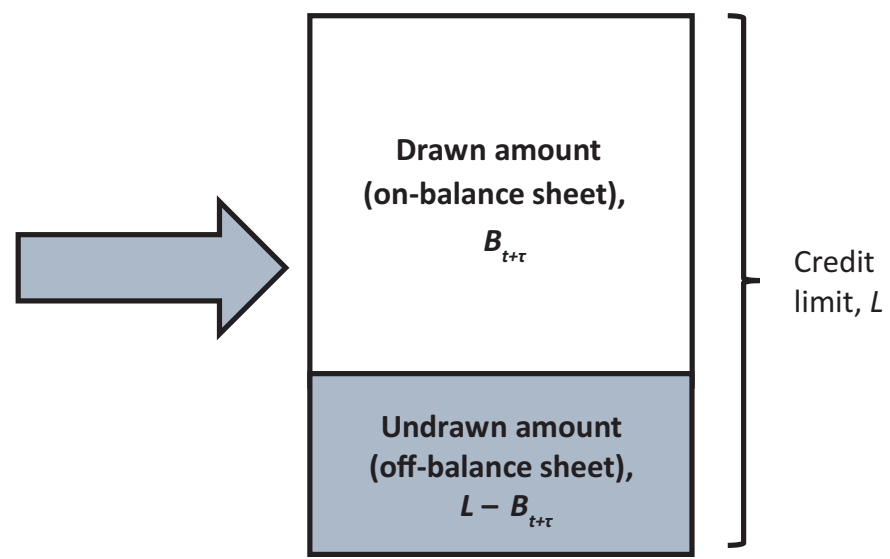

These conversion factors are transparent and logical and are easy to use in practice. Indeed, the drawn amount can increase in the future directly in proportion to the undrawn amount of credit facilities. This relationship is valid for a separate credit facility, but not true for all credit facilities. In fact, off-balance sheet items include credit commitments with different levels of limit usage. Meanwhile, the CCF approach contains a hidden assumption that the level of utilization of credit commitments is the same. As a result, the CCF approach can overestimate or underestimate risks. Nevertheless, Basel's CCF approach has motivated banks to deepen their understanding of their off-balance sheet risks. Usage of CCF and EAD has become so popular among banks that they are planning to use them with the transition to IFRS 9, even though the standard does not implicitly require its use (GPPC, 2016). Meanwhile, practitioners and researchers are faced with problems in directly and accurately estimating conversion factors. This has proved to be a difficult task, for several reasons. The distribution of the CCF is relatively complex and bimodal. It is not defined when the current drawn amount equals the credit limit. The CCF is not stable when the current drawn amount is close to the credit limit. It does not take into account changes in credit limit over time (Moral and de España, 2006). As a result, practitioners and researchers have started to seek alternate approaches. These include the direct investigation of the EAD (Kim and DeVaney, 2001; Taplin and al., 2007; Tong and al., 2016) and the use of new dimensionless target variables such as: 
- The utilization rate (Jacobs, 2009; Yang and Tkachenko, 2012):

$$
U_{t}=\frac{B_{t}}{L}
$$

that is, the ratio of the current outstanding drawn amount to the credit limit, and

- The change in utilization (Jacobs, 2009; Yang and Tkachenko, 2012):

$$
\Delta U_{t}=\frac{B_{t}-B_{t-1}}{L} \equiv U_{t}-U_{t-1}
$$

that is, the ratio of the change in drawn amount to the credit limit.

Both dimensionless target variables have a minimum of 0 and maximum of 1 , meaning its distributions are truncated. This creates difficulties in the use of standard estimation techniques. Numerous results of direct EAD estimates show that the EAD is directly proportional to the credit limit $L$ and has a weak relationship with the current drawn amount $B_{t}$ (for instance, Kim and DeVaney, 2001; Taplin and al., 2007). This proves the utilization rate plays a key role in predicting the drawn amount in the future. In contrast to CCF, the utilization rate $U_{t}$ is well-defined and stable given any outstanding drawn amount. It captures possible changes in the credit limit over time (Moral and de España, 2006). Therefore, the utilization rate is expected to have a better distribution than the CCF's bimodal distribution. Osipenko and Crook (2016) additionally argued that the utilization rate more deeply captures borrowers' behavior, banks' credit policies, and products' parameters. They stated that the prediction of the utilization rate instead of the drawn amount helps avoid possible disproportion in modelling.

The methodological efforts of practitioners and researchers have been predominantly directed at identifying more advanced:

- Univariate distributions for target variables that better describe empirical data. For instance, Tong and al. (2016) proposed a univariate mixture model with a zero-adjusted gamma distribution for the EAD distribution.

- Regression techniques to improve the prediction of drawdowns. For instance, Osipenko and Crook (2016) used advanced estimation techniques such as ordinary linear regression, beta regression, beta transformation plus general linear models, fractional regression, and weighted logistic regression.

Note that the use of univariate distributions does not provide an understanding of how the explanatory variables affect the expected drawn amount of credit facilities. For example, how the current level of the utilization rate influences on the future rate. Unfortunately, regressions only approximately represent the statistical dependence of the predictable and explanatory variables (Korns, 1968). The author did not find any work on the use of joint bivariate distributions for predicting drawdowns. As a result, the author chooses the utilization rate as the target variable and tests the alternative to regressions approach based on the joint truncated distribution of the future and current utilization rates to predict the expected drawn amount.

\section{MODELLING THE UTILIZATION RATE BASED ON DOUBLY TRUNCATED BIVARIATE PROBABILITY DISTRIBUTION}

Let us have historical long-time daily series of the current drawn (on-balance sheet items) and undrawn (off-balance sheet items) amounts of facilities (Figure 1). Knowing these series, we build the historical time series of the utilization rate $U_{t}$. Note that the statistical data should contain a large number of independent credit lines. Time periods should be chosen to include periods when credit limits were fixed. Knowing the series of two random variables $U_{t}$ and $U_{t+\tau^{\prime}}$ we find the joint probability distribution function $f\left(U_{t^{\prime}} U_{t+\tau}\right)$ doubly truncated in the square area: $0 \leq U_{t^{\prime}} U_{t+\tau} \leq 1$. Here we assume the joint bivariate probability distribution function is stationary. We are interested in finding the conditional expected utilization rate (exceeding the current utilization rate $U_{t}$ ) at a future time $(t+\tau)$ if the current utilization rate at time $t$ is given $U_{t}$ :

$$
U_{t+\tau}\left(U_{t}\right)=\mathrm{E}\left(U_{t+\tau} \mid U_{t}\right)
$$

Knowing the joint probability function $f\left(U_{t^{\prime}} U_{t+\tau}\right)$, we gain the conditional probability density function $f\left(U_{t+\tau} / U_{t^{\prime}}\right)$ of variable $U_{t+\tau}$ given $U_{t}$ : 


$$
f\left(U_{t+\tau} \mid U_{t}\right)=\frac{f\left(U_{t}, U_{t+\tau}\right)}{f\left(U_{t}\right)}=\frac{f\left(U_{t}, U_{t+\tau}\right)}{\int_{0}^{1} f\left(U_{t}, U_{t+\tau}\right) \times d U_{t+\tau}}
$$

Taking into account (6), the conditional expected utilization rate is given by:

$$
U_{t+\tau}\left(U_{t}\right)=\frac{\int_{U_{t}}^{1} U_{t+\tau} \times f\left(U_{t+\tau} \mid U_{t}\right) \times d U_{t+\tau}}{\int_{U_{t}}^{1} f\left(U_{t+\tau} \mid U_{t}\right) \times d U_{t+\tau}} \equiv \frac{\int_{U_{t}}^{1} U_{t+\tau} \times f\left(U_{t}, U_{t+\tau}\right) \times d U_{t+\tau}}{\int_{U_{t}}^{1} f\left(U_{t}, U_{t+\tau}\right) \times d U_{t+\tau}} .
$$

Therefore, the formula (7) predicts the conditional expected utilization rate at a future time $(t+\tau)$ given the current utilization rate $U_{t}$ at time $t$. Recall that in order to evaluate expected loan losses, Basel recommends calculating drawdowns on facilities over 12 months, but IFRS 9 requires doing this over the entire lifetime for certain types of impaired loans.

If we have the long time-series of data, we can analyze the joint distributions of pairs of $U_{t}$ and $U_{t+k \times \tau}$ and predict the expected utilization rate for moments in time: $1 \times \tau, 2 \times \tau, \ldots, k \times \tau, \ldots, K \times \tau$. Furthermore, we assume that $\tau=30$ days. Then $k$ denotes the number of month in the periods explored. If the time series is short we can apply the next recursive procedure. Let us have only one distribution of pairs $U_{t}$ and $U_{t+\tau}$. In this case, we can predict the expected utilization rate at the end of the first $(k=1)$ month using formula (7):

$$
U_{t+\tau}\left(U_{t}\right)
$$

Additionally, we calculate the expected utilization rate at the end of the second $(k=2)$ month by the formula taking into account the new input value of the utilization rate $U_{t+\tau}$, i.e.:

$$
U_{t+2 \tau}=U_{t+2 \tau}\left(U_{t+\tau}\right)
$$

Then, we repeat this procedure for the expected utilization rate at the end of each $k^{\text {th }}$ month with the formula:

$$
U_{t+k \times \tau}=U_{t+k \times \tau}\left(U_{t+(k-1) \times \tau}\right) \text {, }
$$

and so on until we cover the entire explored period $T=K \times \tau$.

In order to predict the expected drawn amount (EDA), the inverted formula should be used (3):

$$
E D A_{k} \equiv B_{t+k \times \tau}=U_{t+k \times \tau} \times L .
$$

Unfortunately, the author had available only a relatively short daily time series of the utilization rate for revolving corporate credit lines for one Ukrainian bank denominated in UAH. The data contains information for drawn and undrawn amounts on credit lines over 294 working days.

The calculated utilization rates $U_{t}$ are in a range from 0.5786 to 0.8558 . The current utilization rates $U_{t}$ have:

- a mean of $\mu_{U t}=0.7776$ and

- a standard deviation of $\sigma_{U t}=0.0547$.

We also calculate the statistical parameters for the utilization rates $U_{t+\tau}$ shifted ahead by $\tau=20$ working days:

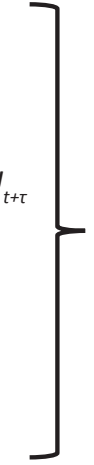

- $\mu_{U t+\tau}=0.7805$;

- $\sigma_{U t+\tau}=0.0508$;

- correlation coefficient $\rho=0.5907$ between $U_{t}$ and $U_{t+\tau}$.

As we have a relative short time series, then we assume, to illustrate the proposed approach, that the joint distribution of $U_{t}$ and $U_{t+\tau}$ are governed by a truncated bivariate normal distribution (Wilhelm and Manjunath, 2010) with parameters (A): 


$$
f\left(U_{t}, U_{t+\tau}\right)=\frac{\exp \left(-\frac{Q\left(U_{t}, U_{t+\tau}\right)}{2 \times\left(1-\rho^{2}\right)}\right)}{\int_{0}^{1} \int_{0}^{1} \exp \left(-\frac{Q\left(U_{t}, U_{t+\tau}\right)}{2 \times\left(1-\rho^{2}\right)}\right) d x d y},
$$

where

$$
Q\left(U_{t}, U_{t+\tau}\right)=\left(\frac{U_{t}-\mu_{U_{t}}}{\sigma_{U_{t}}}\right)^{2}-2 \times \rho \times\left(\frac{U_{t}-\mu_{U_{t}}}{\sigma_{U_{t}}}\right) \times\left(\frac{U_{t+\tau}-\mu_{U_{t+\tau}}}{\sigma_{U_{t+\tau}}}\right)+\left(\frac{U_{t+\tau}-\mu_{U_{t+\tau}}}{\sigma_{U_{t+\tau}}}\right)^{2}
$$

By substituting (13) into (7), we predict the conditional expected utilization rate by the following formula:

$$
U_{t+\tau}\left(U_{t}\right)=\frac{\int_{U_{t}}^{1} U_{t+\tau} \times \exp \left(-\frac{Q\left(U_{t}, U_{t+\tau}\right)}{2 \times\left(1-\rho^{2}\right)}\right) \times d U_{t+\tau}}{\int_{U_{t}}^{1} \exp \left(-\frac{Q\left(U_{t}, U_{t+\tau}\right)}{2 \times\left(1-\rho^{2}\right)}\right) \times d U_{t+\tau}}
$$

Some results of the estimation are presented in Figure 2-3. The calculations were conducted using MathCAD.

Figure 2. The dependences of future utilization rates on current utilization rates

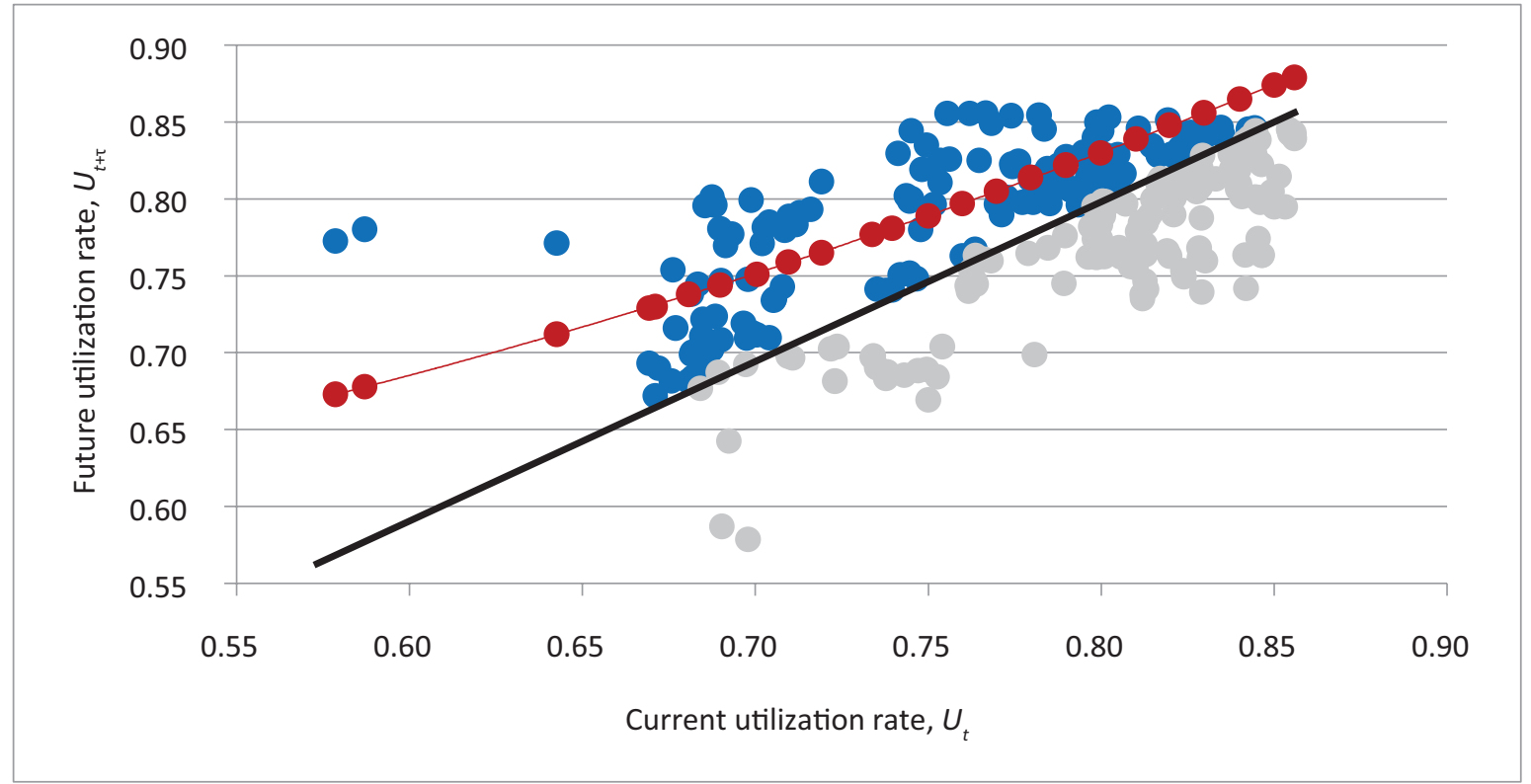

Blue points - actual $U_{t+\tau}>U_{t^{\prime}}$ grey points - actual $U_{t+\tau} \leq U_{t^{\prime}}$ black line $-U_{t+\tau}=U_{t^{\prime}}$ red points - the conditional expected utilization rate $U_{t+\tau}>U_{t^{*}}$

Developed by the author.

Under the assumption that variables $U_{t}$ and $U_{t+\tau}$ are governed by a bivariate normal distribution, the dependence of expected utilization rates on current utilization rates is non-linear (Figure 2) and has an admissible value of $R^{2}=0.57$.

Expressing the formula (2) for the liquidity conversion factor (LCF) in the next equivalent form:

$$
L C F_{k}=\frac{E D A_{k}-B_{t}}{L-B_{t}} \equiv \frac{E D A_{k} / L-B_{t} / L}{1-B_{t} / L}=\frac{U_{t+k \times \tau}-U_{t}}{1-U_{t}} .
$$


The dependences of the expected and actual monthly liquidity conversion factors $L C F$ on the current utilization rate $U_{t}$ are shown in Figure 3.

Figure 3. The dependences of expected and actual monthly liquidity conversion factors LCF on the current utilization rate $U_{t}$



Developed by the author.

As shown in Figure 4, the expected monthly liquidity conversion factor LCF calculated using the proposed approach are well-matched with the actual mean of the LCF of $15 \%$. This value is higher than the $10 \%$ recommended by Basel (BIS, 2013). The example of estimating the expected utilization rate using the recursive procedure (8-11) is shown in Figure 4 and in Table.

Figure 4. Change in the expected utilization rate over time from point $U_{t}=0.7$

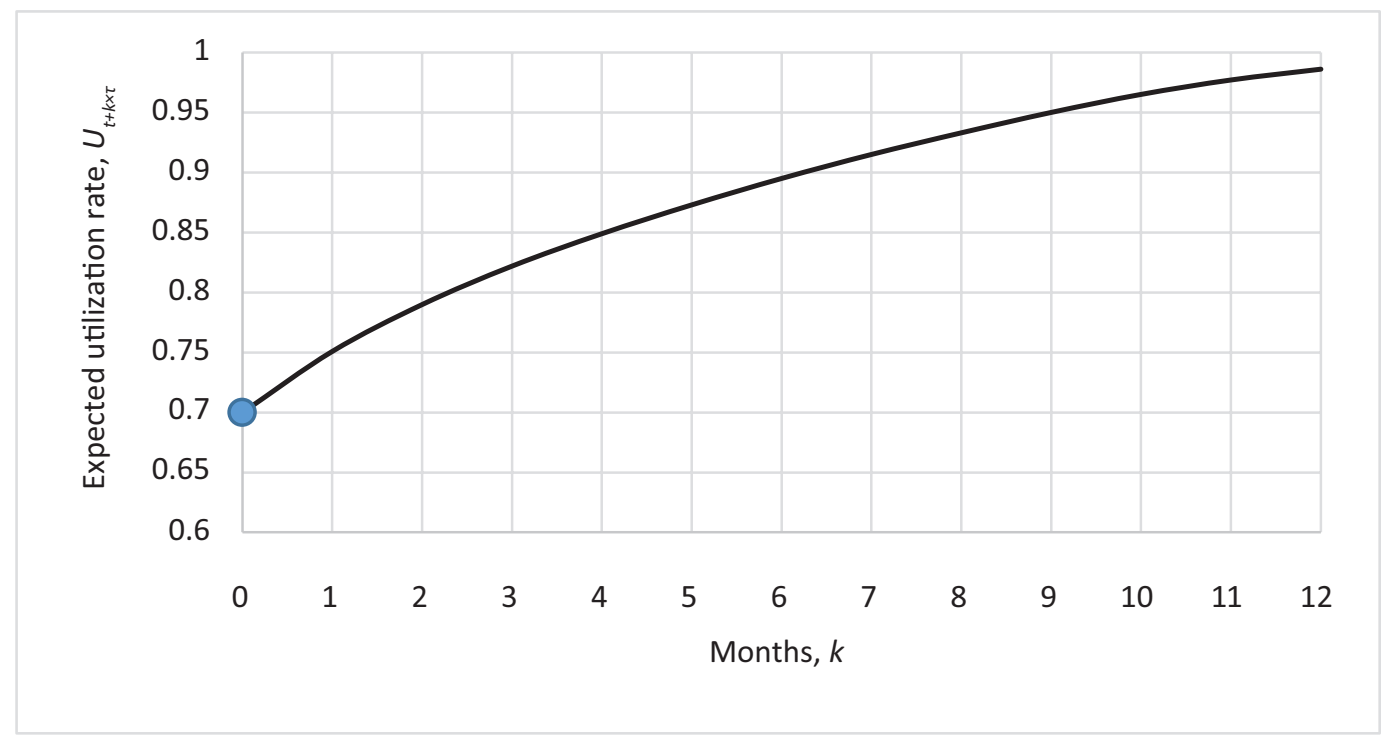

Developed by the author. 
Table. Change in the expected utilization rate over time from point $U_{t}=0.7$

\begin{tabular}{|l|c|c|c|c|c|c|c|c|c|c|c|c|c|c|}
\hline Month, $\boldsymbol{k}$ & 0 & 1 & 2 & 3 & 4 & 5 & 6 & 7 & 8 & 9 & 10 & 11 & 12 \\
\hline$U_{t+k \times \tau}$ & 0.7 & 0.751 & 0.79 & 0.822 & 0.849 & 0.873 & 0.895 & 0.915 & 0.933 & 0.95 & 0.977 & 0.977 & 0.986 \\
\hline
\end{tabular}

Developed by the author.

As shown in Figure 4, the utilization rate of corporate credit lines approaches a value of 1 at the end of the 12-month period. Accordingly, the LCF over the 12 months will be equal to:

$$
L C F_{12}=\frac{0.986-0.7}{1-0.7}=0.953
$$

In order to calculate Exposure At Default $(E A D)$, one should remember that the exposure of credit facilities is variable and dependent on the time of default. Therefore, the Exposure At Default, for instance, over 12 months is calculated by the following formula (Tong at al., 2016):

$$
E A D_{12}=\sum_{k=1}^{12} \frac{S_{k-1}-S_{k}}{1-S_{12}} \times E D A_{k}
$$

where $S_{k}$ is the survival function at month $k^{\text {th }}$ and $\left(S_{k-1}-S_{k}\right)$ gives the probability of default occurring in the $k^{\text {th }}$ month. Note that under IFRS 9, the $12^{\text {th }}$ month period may be lengthened for the loan's lifetime for certain impaired loans. We express the survival function $S_{k}$ through the default probability $p d$ within a month, assuming the default probability does not depend on time, by the well-known relation:

$$
S_{k}=(1-p d)^{k}
$$

Taking into account (17), we re-write formula (16) in the following form:

$$
E A D_{12} / L=\sum_{k=1}^{12} \frac{p d \times(1-p d)^{k-1}}{1-(1-p d)^{12}} \times U_{t+k \times \tau}
$$

Then, the credit conversion factor CCF over 12 months is derived from $E A D_{12}$ and calculated by the following equation (1):

$$
C C F_{12}=\frac{E A D_{12}-B_{t}}{L-B_{t}} \equiv \frac{E A D_{12} / L-B_{t} / L}{1-B_{t} / L}=\frac{E A D_{12} / L-U_{t}}{1-U_{t}}
$$

Consider the following example. Let the monthly expected default probability equal $p d=0.008$. Taking into account the change in the expected utilization rate (Table), we obtain the ratio of exposure to default to credit limit by the formula (18):

$$
E A D_{12} / \mathrm{L}=0.89 \text {. }
$$

And finally, the credit conversion factor over 12 months defined by the formula (19) will be:

$$
C C F_{12}=\frac{0.89-0.7}{1-0.7}=0.63
$$

Note that the value of the CCF is less than the value of the LCF (0.63 compared with 0.953$)$ as the drawn amount is decreased due to defaults. Note that the developed approach is suitable not only to estimate the expected loan losses for allowances and liquidity needs but for capital requirements as well.

\section{CONCLUSION}

This study proposes an alternate approach to predicting the drawn amount on committed credit facilities based on the target variable as the utilization rate and a truncated bivariate normal distribution. The method is simple to use and requires only five parameters: the means and standard deviations for the current and future utilization rates and the correlation coefficient between them. A comparison of the calculated expected and actual utilization rates shows sufficient accuracy for use in practice $\left(R^{2}=0.57\right)$. Obtained in this way, the expected utilization rate can be easily used to estimate the liquidity conversion factor (LCF) for the liquidity coverage ratio, the exposure at default (EAD), and the credit conversion factor (CCF). 
This approach is suitable for estimating liquidity needs and credit losses for provisioning as well as capital requirements. In our opinion, the approach has great potential for further development as it may include several explanatory variables by using a multivariate distribution. Moreover, there are great prospects in using a non-stationary distribution.

Further investigation can be focused on predicting Exposure At Default of so-called "indexed" banking products, such as domestic currency loans with an embedded option on its revaluation based on changes in a foreign exchange rate or other indexes which are becoming popular among Ukrainian banks. The exposures of these products may significantly increase at the time of default, which would pose additional risks to banks. The developed approach also requires testing for other products such as credit card and corporate overdraft facilities.

\section{References}

- BIS (2001). Basel Committee on Banking Supervision. The Standardised Approach to Credit Risk. Supporting Document to the New Basel Capital Accord. Available at: http://www.bis.org/publ/bcbsca04.pdf

- BIS (2013). Basel Committee on Banking Supervision. Basel III: The Liquidity Coverage Ratio and liquidity risk monitoring tools. Available at: http://www.bis.org/publ/bcbs238.pdf

- GPPC (2016). Global Public Policy Committee of representatives of the six largest accounting networks. The implementation of IFRS 9 impairment requirements by banks. Considerations for those charged with governance of systemically important banks. Available at: https://assets.kpmg.com/content/dam/kpmg/pdf/2016/06/gppc-ifrs9-implementation-considerations-20160617.pdf

- IFRS 9 Financial Instruments (replacement of IAS 39). Available at: http://www.ifrs.org/Current-Projects/IASB-Projects/Financial-Instruments-A-Replacement-of-IAS-39-Financial-Instruments-Recognition/Pages/Financial-Instruments-Replacementof-IAS-39.aspx

- Jacobs M. (2009). An Empirical Study of Exposure at Default. Risk Analysis, Division / Credit Risk Modelling Moody's KMV Credit Practitioner's Conference. September 9, 2009. Available at: https://papers.ssrn.com/sol3/Papers.cfm?abstract_ id $=1149407$

- Kim H., DeVaney S.A. (2001). The Determinants of Outstanding Balances among Credit Card Revolvers. Association for Financial Counseling and Planning Education. Available at: https://afcpe.org/assets/pdf/vol1216.pdf

- Korn G.A., Korn T.M. (1968). Mathematical Handbook for Scientists and Engineers. Definitions, Theorems, and Formulas for Reference and Review. Dover Publications, Inc. Mineola, New York.

- Moral G., de Espa-a B. (2006). EAD Estimates for Facilities with Explicit Limits. Available at: https://link.springer.com/chapter/10.1007/978-3-642-16114-8_11/fulltext.html

- National Bank of Ukraine (2016). Resolution No. 351. Regulation for Measuring Credit Risk Generated by Banks' Asset Operations. Available at: https://bank.gov.ua/document/download?docld=33378802

- Osipenko D., Crook J. (2015). The Comparative Analysis of Predictive Models for Credit Limit Utilization Rate with SAS/STAT. Paper No. 3328-2015. Available at: https://support.sas.com/resources/papers/proceedings15/3328-2015.pdf

- Regulation EU No. 575-2013 (2013). The European Parliament and the Council on Prudential Requirements for Credit Institutions and Investment Firms and Amending Regulation (EU) No. 648-2012. Available at: http://eur-lex.europa.eu/legalcontent/EN/TXT/?uri=celex\%3A32013R0575

- Taplin R., To H.M., Hee J. (2007). Modeling exposure at default, credit conversion factors, and the Basel II Accord. Journal of Credit Risk, Vol. 3, No. 2, pp. 75-84. https://doi.org/10.21314/JCR.2007.064

- Tong E.N.C., Mues C., Brown I., Thomas L.C. (2016). Exposure at Default Models with and without the Credit Conversion Factor. European Journal of Operational Research, Vol. 252, No. 3, pp. 910-920. https://doi.org/10.1016/j.ejor.2016.01.054

- Wilhelm S.,Manjunath B.G. (2010). Tmvtnorm: A Package for the Truncated Multivariate Normal Distribution. Contributed Research Articles. The R Journal, Vol. 2/1, June 2010. pp. 25-29. Available at: https://journal.r-project.org/archive/2010/RJ2010-005/RJ-2010-005.pdf

- Yang B.H., Tkachenko M. (2012). Modeling of EAD and LGD: Empirical Approaches and Technical Implementation. Available at: https://mpra.ub.uni-muenchen.de/57298/1/MPRA_paper_57298.pdf 